\title{
1 Feasibility of glued laminated timber beams 2 with tropical hardwoods
}

3 D. Bourreau ${ }^{1} \bowtie$, Y. Aimene $^{1}$, J. Beauchêne ${ }^{1}$, B. Thibaut $^{2}$

4 (1) UAG-UMR Ecofog, Pôle Universitaire Guyanais, 97337 Cayenne Cedex, FRENCH

5 GUIANA.

6 (2) CNRS-LMGC, Université de Montpellier2, 34095 Montpellier, FRANCE

$7 \bowtie$ Damien BOURREAU

$8 \quad$ Phone: $+33(0) 633371695$

$9 \quad$ Email:dbourreau@nancy.inra.fr

\section{Abstract:}

12 A feasibility study of glulam was carried out in French Guiana using local wood species. The aim 13 was to determine gluing parameters affording satisfactory behaviour to manufactured glulam in 14 a tropical climate.

15 Three abundant wood species, with special properties, were selected for the study and 16 Resorcinol-Phenol-Formaldehyde resin was used for bonding. Three industrial parameters were 17 considered: adhesive spread rate, closed assembly time and gluing pressure. Delamination and 18 shearing tests were carried outin accordance with European Standards.

19 The tests revealed the influence of wood properties and manufacturing parameters on joint 20 resistance. In fact, the results showed that specific gravity and the shrinkage coefficientgreatly 21 influenced the gluing step. Indeed, wood with a medium specific gravity needed more adhesive and more pressure than wood with a high specific gravity. In addition, planning and lamella thicknesswere found to affect glue joint resistance. 
2 Nowadays, glued laminated timber is acknowledgedto be a high-performance

3 composite material used in construction. Indeed, this wood product enjoys high

4 mechanical properties, compared to solid wood (Guitard 1994). It is also an

5 economical and ecological material, comparing to concrete or steel, using a

6 renewable resource provided by a sustainable forest management. Despite

7 increasing glulam imports into French Guiana, these wood products need to meet

8 some specific requirements for use in a tropical climate. However, some local

9 wood species from the Amazon forest could be used for glulam manufacturing,

10 avoiding risks of degradation due to the abundance of fungi and termites.

11 The assembling of wood products by gluing depends on many interlinked factors

12 to achieve a single glued assembly. While glulam manufacturing in temperate

13 countries has been mastered, the adhesive bonding of wood components in a

14 tropical climate raises numerous problems. One of the main problems is high

15 temperatures and humidity, which weaken the adhesive and its adhesion (EN 301

16 2006). Consequently, the gluing process is a critical step that can greatly affect

17 adhesion and the mechanical properties of glulam beams manufactured in French

18 Guiana. This step can be defined by various industrial parameters: glue basis

19 weight which is related to the glue spread rate, assembly time which indicates

20 glue polymerization status and the pressure applied to hold lamellae together

21 (Elbez and Bentz 1991). Moreover, tropical hardwood properties, such as a high

22 specific gravity, high shrinkage coefficient, or the presence of resins, are another

23 major bonding problem (Gérard 1999). In order to avoid these problems, the right

24 match has to be established between the gluing parameters, appropriate wood

25 properties and moisture content under tropical conditions (Guiscafre and Sales

261980 intern report). Based on the glulam manufacturing of African hardwoods,

27 past studies (Bedel and Gautier 1972; Guiscafre and Sales 1975, 1980 intern

28 report; Gérard 1999) have shown that closed assembly times need to be shorter

29 than those recommended by the adhesive manufacturer, due to high temperatures

30 in the tropics, which increase resin curing (Bedel and Gautier 1972). A high

31 pressure is not beneficial when gluing wood with a high specific gravity

32 (Guiscafre and Sales 1975, 1980 intern report). Furthermore, careful surface

33 preparation of the lamellae before gluing and a uniform glue joint thickness are

34 required to manufacture a timber beam. Moreover, it appears that a sanded surface

35 does not increase delamination results (Guiscafre and Sales 1980 intern report;

36 Gérard 1999). Lastly, working on hardwoods, Hwang et al. (1993) showed that

37 bonding-strength (evaluated by shearing tests) increases with an increase in the

38 specific gravity of the wood, whereas retention of Resorcinol Phenol

39 Formaldehyde (RPF) adhesive in the wood decreases (Hwang et al. 1993).

40 As there is no standard on the use of hardwood glulam for structural purposes, this

41 innovative structural wood gluing assembly has to be validated by two

42 standardized tests designed for softwood species. The delamination test assesses

43 the resistance of the assembly to shearing and tension perpendicular to the grain 
1 induced by cyclical variations in wood moisture content. It is defined as an ageing

2 test. The block shear test characterizes mechanical resistance of the joint to

3 shearing.

5 In this study, the bondability of hardwoods for glued laminated timber beams was

6 assessed in French Guiana using local wood species. The aim was to establish

7 gluing parameters affording good mechanical properties to glued laminated beams

8 manufactured in a tropical climate.

\section{Materials and methods}

11 The study of the feasibility of glulam with new wood species needs to choose the

12 adequate wood species and adhesive producing the best association wood-

13 adhesive-preservation. The present study focused mostly on the analysis of the

14 combination specie-adhesive. To avoid risks of degradation due to the virulence

15 of fungi and termites, species with natural durability were considered and

16 recommendations in use were provided to enhance the preservation (Bourreau

17 2011).

\subsection{Wood and adhesive properties}

In French Guiana there are almost 1,500 species listed, but wood properties and industrial constraints impose a strict choice of species for glulam manufacture.

The most important physical wood properties are specific gravity, wood shrinkage, anisotropy and satisfactory natural durability. The chosen species were logged according to a sustainable forest management provided by the French

24 Forestry Organisation (ONF) pending PEFC and FSC certifications for French-

25 Guiana area.

26 Three abundant wood species were selected: Qualea rosea, Dicorynia guianensis and Peltogyne venosa. P. venosa and D. guianensis have both sufficient natural durability when not used in ground contact, whereas the $Q$. rosea needs a soak treatment when used in exterior condition. However, working on the gluing of treated hardwoods, Janowiack et al (1992) and Paes et al (2009) show good bonding results between RPF adhesive and CCA treatment. In this study, a softwood specie, Larix decidua, commonly used in temperate countries was considered as a reference species (CIRAD 2008). Some wood properties can be found in technical documents for Guianese wood species (CTFT 1999, EN 335-2 2006) and they are summed up in table 1.

A wide variety of adhesives is available on the market, but depending on end-uses, requirements are different and are regulated by European standards. Thus, given the structural purposes under tropical conditions, the choice of adhesives is limited to two types, a Melamine-Urea-Formaldehyde (MUF) and a

40 Resorcinol Phenol Formaldehyde (RPF) (EN 301 2006). However, bonding tests on the selected tropical species (Bourreau 2011) showed that the MUF is sensitive 
1 to the surrounding environmental conditions of high temperatures and high

2 humidity and is not recommended to be used in a manufacturing process under

3 tropical conditions. This observation was also reported by Custodio et al.(2008).

\section{$4 \quad 2.2 \quad$ Bonding durability tests}

5 To assess bonding efficiency, delamination and block shear tests were used in this

6 study in accordance with European standards EN 391: 2002 and EN 392: 1995

7 respectively.

\section{$8 \quad 2.2 .1$ Delamination}

9 The delamination test is used to assess the resistance of the glue joint after ageing

10 cycles including strong variations in wood moisture content. As wood dimensions

11 vary during use depending on changes in ambient humidity, delamination assesses

12 the resistance of the glued assembly under those variations. Depending on the

13 service classes for which the end-product is to be used, different delamination test

14 procedures exist relative to the risk levels assessed for the wood product (EN 391

15 2002). Thus, for glulams used in service class 3, outdoor conditions, delamination

16 tests were carried out according to procedure A, described in EN 391: 2002

17 standard. This involved three cycles of water immersion with a pressure of 6 bars,

18 then drying between 60 and 70 degrees Celsius until the specimen reached its

19 initial weight (around 22 hours).

21 Measurements were taken along the glue lines on each cross-section of the

22 specimen. The total delamination of a specimen $\left(D_{\mathrm{s}}\right)$ was calculated, which

23 expresses the proportion of the delamination length of all glue lines $\left(l_{\mathrm{DS}}\right)$

24 compared to the total length of all the glue lines of a specimen $\left(l_{\mathrm{s}}\right)$, as illustrated in 25 the next equation.

$$
D_{S}(\%)=\frac{l_{D S}}{l_{S}} \times 100
$$

27 Delamination was measured to an accuracy of $0.1 \mathrm{~mm}$. This value was compared

28 to the upper limit allowed by the European standards, i.e. $10 \%$ for tropical

29 hardwoods.

2.2.2 Block shear strength and wood failure.

32 The block shear test is used to assess the shear mechanical resistance parallel to

33 the grain of the glued assembly (EN 392 1995). Indeed during glulam beams

34 loading, the shear is a major failure mode of the interfaces of the lamellae. At the

35 end of the shearing test, the adherence of the glue joint is also assessed on the

36 faces of the sheared samples in order to determine the weakened part of the

37 composite, either the adhesive or the wood. 
1 Shear tests were carried out on specimens with square areas in accordance with

2 EN 392: 1995. Shear-strength testing was conducted using an MTS machine with

3 a constant crosshead displacement rate. During the tests, most failures occurred

4 within 20secondes. The wood failure percentage was estimated to the nearest $5 \%$

5 of explored shear area. The requirement, according to EN 386: 2002 is a

6 combination between maximum shear strength $\left(f_{v}\right)$ and wood failure percentage

7 (WFP), which is the percentage of wood on the sheared surface. Requirements for

8 individual and average values are given in table 2. However, past studies on the

9 bondability of African hardwoods considered that block shear testing is successful

10 when glue line shear-strength reaches at least $80 \%$ of solid wood shear resistance

11 (Guiscafre and Sales 1975).

\subsection{Experimental data plan}

15 In order to evaluate the effect of bonding conditions on glued assembly durability

16 for glulam manufacturing under the climatic conditions in French Guiana (average

17 temperature: $30^{\circ} \mathrm{C}$, relative humidity: $85 \%$ ), three industrial parameters were

18 considered: spread rate $\left(\mathrm{g} / \mathrm{m}^{2}\right)$, Closed Assembly Time (CAT in min), defined as

19 the time from assembly until the application of pressure, and clamping pressure

20 (MPa).

\section{$21 \quad 2.3 .1 \quad$ Experimental procedure}

22 In this study, 92 glulam beams composed from three wooden slats were

23 manufactured and tested. Depending on the lamellae thickness $(e)$, the size of the

24 beams was $3 e \times 100 \times 700 \mathrm{~mm}^{3}$. Beams were manufactured from boards, air-dried in

25 the local atmosphere until they had reached a balanced moisture content MC. The

26 balanced MC observed on the guianensis species was 14, 16 and $17 \%( \pm 2 \%)$ for

$27 P$. venosa, D. guianensis and $Q$. rosea respectively. This difference could be

28 explained by an experimental fluctuation induced by the season when the test, and

29 so the MC measures, were done. Because boards were air-stabilized, moisture

30 content recorded during the dry season will be lower than the $\mathrm{MC}$ recorded at the

31 wet season.

33 The clamping pressure was applied by a traditional screw press. The pressure was

34 controlled by a torque wrench. After at least 8 hours' pressurization to ensure

35 almost full bonding strength, all the glulam beams were conditioned in the

36 ambient climate for at least 2 weeks before any handling. Afterwards, beams are

37 planned and full cross-sectional slats were cut from each beam, alternating one

38 specimen for the delamination test and one for the shear test. A total of 5 samples

39 of dimension 3 ex $90 \times 75 \mathrm{~mm}^{3}$ for the delamination test and 4 samples of dimension

$403 \mathrm{e} \times 45 \times 45 \mathrm{~mm}^{3}$ for the shear tests were produced per beam to ensure good 
representativeness of bonding. No loading (bending, etc.) has been applied on the

2 beams before delamination or shear tests.

3 Before testing, the joint thickness of each beam was measured under an electronic

4 microscope on samples reserved for the shear test, in order to determine the actual

5 amount of glue present at the bonding interface. In fact, the actual glue spread rate

6 depends on the squeeze-out of adhesive during the pressing steps, table 3 and the

7 part of the adhesive absorbed by lamellae(Bourreau2011). According to the

8 standards, the samples used for shear tests are stabilized around a moisture

9 content (MC) of $12 \%$ and cut in standard dimensions just before performing the

10 tests. This avoids sample shrinkage.

\subsubsection{Bonding tests}

13 To conduct this study, 3 sets of experiments were carried out. They are

14 summarized in table 3 . The $1^{\text {st }}$ set examined the influence of surface preparation

15 before bonding. The $2^{\text {nd }}$ set, the main one in this study, focused on the effect of

16 the industrial parameters described previously on the bonding of each wood

17 species studied (Q. rosea, P. venosa, D. guianensis and L. decidua). In this set of

18 tests, the glue was spread on both sides of the boards. The values of the tested

19 gluing parameters used in the first two sets were selected on the basis of the

20 adhesive manufacturer recommendations, that advised to glue with $750 \mathrm{~g} / \mathrm{m}^{2}$ per

21 face with a clamping pressure of the $1 \mathrm{MPa}$ and a CAT of 20 minutes at $30^{\circ} \mathrm{C}$.

22 Finally, a set of validation tests was carried out on the species with good

23 delamination results established in the $2^{\text {nd }}$ set of tests. In addition, the effect of

24 lamella thickness on delamination was investigated, in order to improve bonding.

\section{Results and discussion}

In this part, the results of the delamination and the block shear tests are presented.

They are followed by a discussion that explains the influence of the considered parameters (Glue spread rate, CAT and Pressure) on the bonding of the glulam.

\subsection{Delamination results}

\subsubsection{Planning influence}

Firstly, the influence of surface preparation was examined by means of the $1^{\text {st }}$ set of delamination tests. Table 4 shows the delamination results for 3 gluing conditions obtained on specimens planned more than a day before gluing and glued a maximum of $8 \mathrm{~h}$ after planning.

This table shows that the delamination factor was greatly affected by surface preparation. The results show that a surface glued more than 24 hours after planning interfered with the adhesion of the resin. It appears that the wood surface needed to be refreshed just before the gluing step to avoid contamination of the surface by wood chemicals, which are very present in hardwoods and migrate to 
1 the surface (Nussbaum and Sterley 2002). This step therefore prepares the wood

2 support, to give good anchorage of the adhesive to its surface and also enhances

3 the physical and chemical links between its surface and the glue (Nussbaum and

$4 \quad$ Sterley 2002; Gindl et al. 2004). In temperate countries, when gluing softwood

5 species, it is recommended to spread the adhesive within a day (Nussbaum and

6 Sterley 2002). In our case it seemed that gluing within 8 hours after planning was

7 very beneficial.

\subsubsection{Glue spread rate influence}

The effect of the glue spread rate on delamination was examined in the $2^{\text {nd }}$ set of tests. The results are given in figure 1 for the three wood species used. In this figure, one point represents the average delamination recorded on the 5 samples obtained from the same beam.

On this graph, the first observation is that the amount of adhesive measured on the glue joint of the samples was much lower than the quantity applied. Despite some good results for samples with a thin glue joint, delamination results greatly varied and were well over the $10 \%$ limit allowed by the European standard. Moreover, the reference softwood species, L. Decidua, gave very good results. In fact, when glued under the same conditions, the samples of the reference species had a significantly greater glue joint thickness and therefore resisted cracking and joint opening during the severe moisture variations.

We also found that higher delamination results $\left(D_{s}=80 \%\right)$ were achieved with wood species displaying higher swelling coefficients (Q.rosea: $\mathrm{R}_{\mathrm{B}}=14.44 \%$ ), whereas the wood displaying lower swelling coefficients ( $P$. venosa) showed less delamination $\left(D_{s}=40 \%\right)$ and low variability in the results. Indeed, the higher the swelling coefficient of the bonded wood, the higher was the delamination risk, due to greater tensile and shearing stresses at the gluing interface, induced by the moisture variations.

Lastly, figure 1 illustrates that, for $P$. venosa and $D$. guianensis, the specimens with a glue spread rate over $180 \mathrm{~g} / \mathrm{m}^{2}$ at the joint interface had delamination results under the standard limit of $10 \%$.

In order to analyse the effect of the glue spread rate on delamination resistance for the three species, a generalized additive model (GAM) was used (figure 2).

Figure 2 shows the general trends of dependence of the bonding of the three species on the glue spread-rate. The black line represents the mean effect of glue spread rate on delamination and the dotted lines represent its $95 \%$ confidence interval. When these three lines become positive or negative, it means that the influence of glue spread rate parameter is meaningful. Thus, Figure 2 shows no significant dependence for $Q$. rosea (a) within the range of $80 \mathrm{~g} / \mathrm{m}^{2}-135 \mathrm{~g} / \mathrm{m}^{2}$. In fact, the recorded quantity of glue on the bonding interface was very small, and cannot identify any dependence. For $P$. venosa (b) and D. guianensis (c), the plot 
shows a high dependence and give a general trend. It appeared that the larger the

2 amount of adhesive was on the bond, the lower was the delamination factor.

3 Lastly, this analysis identified the lower limit needed to obtain acceptable

4 delamination results for structural bonding. The amounts were respectively

$5 \quad 175 \mathrm{~g} / \mathrm{m} 2$ and $220 \mathrm{~g} / \mathrm{m} 2$ for $P$. venosa and D.guianensis determined graphically

6 when the mean effect and its confidence interval become negative on the figure.

\subsubsection{CAT and Pressure influences}

9 In order to analyse the effect of the other gluing parameters on delamination 10 resistance, statistical analyses of variance (ANOVA) were performed using the 11 CAT and the pressure level $\mathrm{P}$ as variables and the interaction between them (table 12 5).And figure 3 presents graphically the influence of pressure (1) and CAT (2) on 13 delamination results of the three Guianese wood species. Black lines on this figure

Table 5 shows the effect of gluing parameters on the delamination resistance of the three Guianese wood species used. The results showed that the CAT greatly affected $D$. guianensis but not $Q$. rosea and $P$. venosa. On figure 3 (a2 and c2), it appeared that best results were obtained when the CAT was shortest (5 minutes), and maximum delamination occurred when the CAT was 10 minutes long. Likewise, the pressure level was only significant for $P$. venosa. Indeed, the results showed that a low pressure level was needed to prevent delamination (figure $3 \mathrm{~b} 1$ ). For Q.rosea, table 5 reveals a significant effect of the coupling agent $\mathrm{P}$ and CAT. For this species, it appeared that the higher the applied pressure level was, the longer the CAT needed to be in order to obtain sufficient bonding.

\subsection{Block shear results}

As well as the delamination tests, the 27 gluing conditions given for the $2^{\text {nd }}$ set of tests (table 3) were also tested, in accordance with the European standard, to assess glue joint shear resistance. Figure 4 gives the block shear results for the $2^{\text {nd }}$ set of tests, as a function of the maximum shear resistance, $f_{v}$, and the wood failure percentage (WFP) of the assembly. Figure 4a shows all individual values and Figure $4 \mathrm{~b}$ the mean values of the 54 beams tested per species. On each graph, black line represents the WFP minimum value to reach according to EN386: 2002. Dotted lines represent the requirements proposals made by Aicher and Ohnesorge(2011) when tested beech glulam.

35 The block shear test gave an average strength $f_{v \text {, mean }}$ per species of around 13.5, 14.7 and $13.5 \mathrm{MPa}$ for $Q$. rosea, $P$. venosa and D. guianensis respectively.

37 Despite some minor differences between wood species, the block shear strength of 38 the individual specimens ranged between 4.3 and $21.7 \mathrm{MPa}$ and the wood failure

39 percentage from 15 to $100 \%$. It appeared that $4 \%$ of all the specimens tested 40 displayed low shear strength (from 4 to $6 \mathrm{MPa}$ ), $11 \%$ had medium shear strength (from 6 to $11 \mathrm{MPa}$ ) and $85 \%$ showed high shear resistance (over $11 \mathrm{MPa}$ ). This 
last resistance class presents results close to the shear strength recorded for solid

2 wood samples $\left(f_{v,- \text { mean-solid }}=13.3,15.0\right.$ and $13.8 \mathrm{MPa}$ for $Q$. rosea, $P$. venosa and $D$.

3 guianensis respectively). Indeed, the shear resistance ratios between glulam, at its

4 glue joint, and solid wood, recorded on each specimen, were from $80 \%$ to $125 \%$.

5 Moreover, each specimen with a low shear strength $f_{v}$ presented a major lack of

6 adherence, characterized by low wood failure percentages. Thus, 16 specimens

7 and 1 beam failed the block shear test. It is important to note that the beams which

8 failed the shearing test also failed the delamination test, whereas the beams that

9 failed the delamination test could pass the block shear one. In accordance with

10 Aicher and Ohnesorge (2011), requirements made on the block shear test standard

11 (EN 386: 2002) is set too low when using hardwoods. And requirements proposed

12 by these authors (dotted lines) are rather rigorous and permit to identify more

13 beams which failed the delamination test (30 specimens and 8 beams here).

Lastly, these results on tropical hardwoods did not show any specific gravity

effects on bond shear strength, as reported by Hwang et al. (1993).

\subsection{General Discussion}

The above delamination and shearing results showed that gluing parameters were interdependent and needed to be matched to each wood species. Indeed, dense wood was greatly affected by the pressure level (case of $P$. venosa). On the other hand, the relation between CAT and pressure had a major effect on glue joint resistance for a softer wood $(Q$. rosea). Obviously, the amount of glue spread on the surface needs to be sufficient to ensure good adhesion and to be resistant to lamella swelling and shrinkage during delamination tests, especially in the case of wood with a high shrinkage coefficient. High pressure can squeeze out the adhesive from the interface or lead to excessive penetration into the substrate, especially when the glue has not already hardened. In the case of D. guianensis, the CAT greatly influenced the delamination resistance of the bonds, especially due to the tropical climatic conditions observed during the gluing step despite the good wettability of this species (Bourreau 2011). When the assembly time was very long, the ambient temperature increased resin cure, preventing its penetration into vessel and cell walls, leading to weak joint anchorage.

As regards block shear resistance, the results arising from this study showed that $86 \%$ of the samples passed the block shear test, despite the unsatisfactory delamination results on the samples with the same gluing conditions. This tallies with the results reported by Aicher and Ohnesorge (2011) on beech glulam,

40 highlighting that the standard shear test requirements are set too low to validate a

41 structural glued assembly made from hardwoods. It appears that the block shear

42 test identifies glue joints displaying a major lack of adherence and can easily assess if the strength of the glued assembly is similar to that of solid wood. 
2 Lastly, these two standard tests complement each other, but the delamination test

3 is the strictest, involving joint opening by both tension and shearing perpendicular

4 to the grain due to rapid and severe humidity variations.

\section{$6 \quad 3.4 \quad$ Validation of gluing parameters}

7 The above results seemed to qualify $D$. guianensis for glulam manufacturing in

8 French Guiana, other species need more investigations. Consequently, the $3^{\text {rd }}$ set

9 of tests was carried out on this species with the gluing parameters fixed in table 3.

10 For industrial purposes, the time to assemble beams before applying pressure

11 needed to be longer than 20 minutes, so the CAT was extended to 40 minutes. In

12 this set of tests, glue was spread on one face. The delamination results for these

13 tests were in accordance with the European standard, with an average

14 delamination of $5.9 \%$. However, $12 \%$ of the samples recorded delamination over

$1510 \%$ (a maximum of $12.7 \%$ ).

16 The results for the block shear test are given in table 6. Based on the European

17 standards, all the samples successfully passed the block shear test and the strength

18 ratio between glulam joints and the solid wood exceeded $80 \%$.

19 In order to improve the resistance of the samples to delamination, the effect of

20 lamella thickness on delamination risks was investigated in this set of tests,

21 making it possible to determine an adequate thickness that reconciles the cost of

22 glulam production with the resistance of the bond to severe moisture variations.

23 Figure 4 shows delamination results for each lamella thickness group considered

24 in table 3.

25 The results show that the thinner the bonded lamella thickness was, the better was

26 the glulam resistance to delamination. It appeared that at around $28 \mathrm{~mm}$, average

27 delamination was below the limit set by the European standard. However, the

28 thinner the lamella thickness was, the higher was the cost of glulam production.

29 This was mostly due to more adhesive use and also to greater wood wastage

30 during manufacturing. Consequently, a thickness of $28 \mathrm{~mm}$ appears to be the

31 optimum lamella thickness for manufacturing D.guianensis glued laminated

32 timber in French Guiana (Bourreau 2011).

33 The effect of lamella thickness is in keeping with the results reported by

34 Ohnesorge et al. (2010) who analysed beech wood beams with lamella thicknesses

35 of 29,35 and $38 \mathrm{~mm}$. The high delamination rates observed may have been

36 related to the increase in wood swelling under moisture variation. This was also

37 observed when using a wood species with a high shrinkage coefficient ( $Q$. rosea).

38 In order to prevent high swelling stress during the delamination test, the lamella

39 thickness could be reduced and the same sawing pattern needs to be used for the

40 beam assembly. 


\section{Conclusions and recommendations}

2 Depending on the wood species used, the delamination results showed significant

3 gluing parameter effects. Prior to being bonded, the board needed to be planned

4 just before adhesive application and it appeared that the glue joint needed a

5 minimum thickness to provide a satisfactory assembly that could resist severe

6 moisture variations. Consequently, gluing parameters need to be adjusted to the

7 wood species, especially in a tropical climate. Moreover, the current delamination

8 test seemed to be too strict and may not be easy to use or adapt to validate a

9 structural glued assembly using tropical hardwoods.

10 Lastly, to prevent cracks along the glue joint, due to moisture variations, the board

11 thickness can be decreased. An optimum of $28 \mathrm{~cm}$ was adopted for D. guianensis

12 glulam manufacturing in French Guiana. As regards the block shear test, it was

13 successfully passed by almost all the glulam specimens despite a lack of adhesive

14 observed in a large number of samples.

15 Despite some gluing conditions validated by European standards for D.guianensis

16 glulam manufacturing more research is needed to determine gluing conditions for

17 the other two wood species. In the case of $Q$. rosea, the amount of glue needs to

18 be increased and, in order to avoid high shrinkage constraints, the lamella

19 thickness should be decreased. For the densest wood, P. venosa, the pressure level

20 needs to be decreased in order to prevent glue from being squeezed out of the

21 joint. The validation of some gluing conditions needs to focus on the delamination

22 test, and the block shear test should be used to characterize joint resistance.

23 In the future, prior to industrializing Guianese glulam, the resistance of finger

24 jointing assembly has to be tested in order to validate the use of these tropical

25 species for glulam industry.

\section{References}

Aicher S and Ohnesorge D (2011) Shear strength of glued laminated timber made from European beech timber. Eur. J. Wood. Prod. 69: 143-154

Bedel J and Gautier R (1972) Glued laminated structures from tropical hardwoods. Bois et Forêts des Tropiques 141: 51-72

Bourreau D (2011) Etude de faisabilité de lamellé-collé endémique en Guyane Française. Thesis, Université des Antilles et de la Guyane, Cayenne,pp164

34 Centre International de Recherche Agronomique pour le Développement (2008) Mélèze. Technical data sheet, pp 2

36 Centre Technique Forestier Tropical (1999) Bois de Guyane : Gonfolo, Angélique,

37 Amarante. Technical data sheet, Euroimpressions,pp4 
1 Elbez $G$ and Bentz D (1991) Le collage du bois. La technologie du bois.CTBA Paris

2 EN 392 (1995) Glued laminated timber - Shear test of glue lines

3 EN 391 (2002) Glued laminated timber - Delamination test of glue lines

4 EN 386 (2002) Glued laminated timber - Performance requirements and minimum

5 production requirements.

6 EN 301 (2006) Adhesives, phenolic and aminoplastic, for load-bearing timber structures-

7 Classification and performance requirements

8 EN 335-2 (2006) Durability of wood and wood-based products - Definition of use classes

9 - Part 2: Application to solid wood

10 Gérard J (1999) Les spécificités du collage des bois tropicaux : valorisation des essences

11 secondaires et collage multi-essences. Annales Génie Civil Bois numéro spécial Collage

12 Structurel, $15-30$

13 Gindl M, Reiterer A, Sinn G and Stanzl-Tschegg SE (2004) Effects of surface ageing on

14 wettability, surface chemistry and adhesion wood. Holz RohWerkst 62: 273-280

15 Guiscafre J and Sales C, (1975) Etude de l'aptitude du Movingui (Disthemonanthus

16 benthamianus) à l'utilisation en lamellé-collé. Bois et Forêts des Tropiques 161 : 35-40

17 Guiscafre J and Sales C, (1980) Etude de l'aptitude au collage du bois d'Azobé (Lophira

18 alata) à partir de résine Résorcine-Formaldéhyde, Centre Technique Forestier Tropical,

19 Intern report, Nogent-Sur-Marne, pp 19

20 Guitard D (1994) Comportement mécanique du bois. In: ARBOLOR (ed) Le bois matériau

21 d'ingénierie, Nancy, pp 91-125

22 Hwang GS et al(1993)Gluing properties of high-density hardwoods. Mokuzai Gakkaishi 23 39(3): 363-367

24 Janowiak JJ, Manbeck HB, Blankenhorn PR and Kessler KR (1992) Strength properties of 25 exterior adhesives on preservative-treated hardwoods. For Prod J 42 (10): 68-76

26 Nussbaum RM and Sterley M (2002)The effect of wood extractive content on glue

27 adhesion and surface wettability of wood. Wood and Fiber Science 34(1): 57-71

28 Ohnesorge D, Richter K and Becker G(2010) Influence of wood properties and bonding

29 parameters on bond durability of European Beech (Fagus sylvaticaL.) glulams. Ann. For.

30 Sci., 67: 601

31 Paes JB, de Oliveira AKF, de Oliveira E, de Lima CR (2009) Physical-mechanical

32 characterization of the glue laminated bamboo (Dendrocalamus giganteus). Ciencia

33 Florestal 19 (1-2):41-51

34 
2 Table 1 Properties of selected wood species

3 Table 2 Normalized values for a successfulblock shear test (EN 386: 2002)

4 Table 3 Recap of the bonding tests

5 Table4 Effect of planning on delamination for 3 different gluing conditions

6 Table5 Effects of the CAT and P parameters on the delamination factor Ds

7 Table6 Block shear test results for $D$. guianensis ( $3^{\text {rd }}$ set of tests)

Table 1 Properties of selected wood species

\begin{tabular}{|l|l|l|l|l|l|l|}
\hline Wood species & $\mathbf{S}_{\mathbf{G}}$ & $\mathbf{R}_{\mathbf{B}}$ & $\mathbf{R}_{\mathbf{t}}$ & $\mathbf{R}_{\mathbf{r}}$ & $\mathbf{R}_{\mathbf{t}} / \mathbf{R}_{\mathbf{r}}$ & $\mathbf{H C}$ \\
\hline Qualea Rosea & 0.70 & 14.44 & 9.74 & 5.80 & 1.68 & 2 \\
\hline Dicorynia guianensis & 0.79 & 13.50 & 8.24 & 5.13 & 1.61 & 3 \\
\hline Peltogyne venosa & 0.84 & 11.47 & 6.80 & 4.83 & 1.41 & 3 \\
\hline Larix decidua & 0.60 & 11.92 & 8.20 & 4.20 & 1.95 & 3 \\
\hline
\end{tabular}

$\mathrm{S}_{\mathrm{G}}$ : Mean specific gravity

$11 \mathrm{R}_{\mathrm{B}}, \mathrm{R}_{\mathrm{t}}$ and $\mathrm{R}_{\mathrm{r}}$ : total, tangential and radial shrinkage coefficients respectively (\%).

12 HC: Hazard Class (EN 350-2: 2007)

Table 2 Normalized values for a successful block shear test (EN 386: 2002)

\begin{tabular}{|c|c|c|c|c|c|c|}
\cline { 2 - 7 } \multicolumn{1}{c|}{} & \multicolumn{4}{c|}{ Average } & \multicolumn{3}{c|}{ Individual Values } \\
\hline Shear strength $\mathrm{f}_{\mathrm{v}}$, in MPa & 6 & 8 & $\mathrm{f}_{\mathrm{v}}>11$ & $4<\mathrm{f}_{\mathrm{v}}<6$ & 6 & $\mathrm{f}_{\mathrm{v}}>10$ \\
\hline Minimum WFP, in\% & 90 & 72 & 45 & 100 & 74 & 20 \\
\hline
\end{tabular}

Table 3 Recapitulation of the bonding tests

\begin{tabular}{|c|c|c|c|}
\hline Specifications & $1^{\text {st }}$ Set & $2^{\text {nd }}$ Set & $3^{\text {rd }}$ Set \\
\hline Wood species & Q. rosea & $\begin{array}{l}\text { Q. rosea } \\
\text { D. guianensis } \\
\text { P. venosa } \\
\text { L. decidua }\end{array}$ & D. guianensis \\
\hline Adhesive type & \multicolumn{3}{|c|}{ RPF } \\
\hline Adhesive/hardener(ratio) & \multicolumn{3}{|c|}{$100 / 20$} \\
\hline Lamella thickness & \multicolumn{2}{|c|}{$28 \mathrm{~mm}$} & $16 / 22 / 28 / 34 \mathrm{~mm}$ \\
\hline $\begin{array}{l}\text { Maximum time between planning } \\
\text { and bonding }\end{array}$ & $>24 \mathrm{~h} / \leq 8 \mathrm{~h}$ & \multicolumn{2}{|c|}{$\leq 8 \mathrm{~h}$} \\
\hline Adhesive spreading & \multicolumn{2}{|c|}{2 faces } & 1 face \\
\hline Adhesive spread rate $\left(\mathrm{g} / \mathrm{m}^{2}\right)$ & $750 / 1500$ & $250 / 750 / 1500$ & 300 \\
\hline CAT (min) & $10 / 20$ & $5 / 10 / 20$ & 40 \\
\hline Pressure $(\mathrm{MPa})$ & $0.7 / 1$ & $0.4 / 0.7 / 1$ & 1 \\
\hline $\begin{array}{l}\text { Total beams/delamination } \\
\text { specimens/shear specimens (per } \\
\text { species) }\end{array}$ & $6 / 60 / 0$ & $54 / 270 / 216$ & $32 / 160 / 0$ \\
\hline
\end{tabular}


2 Table4 Effectof planning on delamination for 3 different gluing conditions

\begin{tabular}{|l|l|l|l|l|l|l|}
\hline \multirow{2}{*}{$\begin{array}{l}\text { Maximum } \\
\text { time between } \\
\text { planning and } \\
\text { gluing }\end{array}$} & \multicolumn{5}{|l|}{$\begin{array}{l}\text { Delamination results }(\%) \text { depending on gluing parameters } \\
\text { Spread rate }\left(\mathrm{g} / \mathrm{m}^{2}\right) / \text { CAT }(\mathrm{min}) / \text { Pressure }(\mathrm{MPa})\end{array}$} \\
\cline { 2 - 7 } & $1500 / 10 / 0.7$ & $750 / 10 / 0.7$ & $750 / 20 / 1.0$ \\
\cline { 2 - 7 } & Mean & Stdv & Mean & Stdv & Mean & Stdv \\
\hline$>24 \mathrm{~h}$ & 61.4 & 9.5 & 35.2 & 13.0 & 12.3 & 6.3 \\
\hline$\leq 8 \mathrm{~h}$ & 19.5 & 11.2 & 14.6 & 8.4 & 6.0 & 5.3 \\
\hline
\end{tabular}

3 Stdv: Standard deviation

4

5 Table5 Effects of the CAT and P parameters on the delamination factor Ds

\begin{tabular}{|l|l|l|l|l|l|l|}
\hline Wood species & Source & DOF & $\begin{array}{l}\text { Sum of } \\
\text { squares }\end{array}$ & $\begin{array}{l}\text { Mean of } \\
\text { squares }\end{array}$ & F-value & P \\
\hline \multirow{4}{*}{ Q. rosea } & $\mathrm{P}$ & 5 & 0.033 & 0.007 & 0.197 & 0.964 \\
\cline { 2 - 7 } & $\mathrm{CAT}$ & 0 & 0.000 & & & \\
\cline { 2 - 7 } & $\mathrm{P}^{*} \mathrm{CAT}$ & 12 & 1.015 & 0.085 & 2.543 & $0.004^{* *}$ \\
\hline \multirow{4}{*}{ D. guianensis } & $\mathrm{P}$ & 0 & 0.000 & & & \\
\cline { 2 - 7 } & $\mathrm{CAT}$ & 2 & 3.484 & 1.742 & 44.887 & $<0.0001^{* *}$ \\
\cline { 2 - 7 } & $\mathrm{P}^{*} \mathrm{CAT}$ & 15 & 1.278 & 0.085 & 2.196 & 0.007 \\
\hline \multirow{3}{*}{ P. venosa } & $\mathrm{P}$ & 5 & 0.223 & 0.045 & 3.522 & $0.004^{* *}$ \\
\cline { 2 - 7 } & $\mathrm{CAT}$ & 0 & 0.000 & & & \\
\cline { 2 - 7 } & $\mathrm{P}^{*} \mathrm{CAT}$ & 12 & 0.105 & 0.009 & 0.694 & 0.757 \\
\hline
\end{tabular}

DOF: Degrees of freedom

$7 *$ Coupling agent

$8{ }^{* *}$ Significant for $\mathrm{p}<0.005$. The smaller $\mathrm{p}$, the more significant the effect

9

Table6 Block shear test results for D. guianensis ( $3^{\text {rd }}$ set of tests)

\begin{tabular}{|l|c|c|}
\cline { 2 - 3 } \multicolumn{1}{c|}{} & $\boldsymbol{f}_{\boldsymbol{v}}(\mathbf{M P a})$ & WFP (\%) \\
\hline Min & 11.67 & 40 \\
\hline Mean & 15.48 & 79 \\
\hline Max & 19.57 & 100 \\
\hline
\end{tabular}

11 
1 All figures were provided by R software except for figure 1 which was realized by Excel

22007.

\section{Figure legends:}

$4 \quad$ Fig.1 Influence of measured glue spread rate on delamination results

$5 \quad$ Fig.2 Influence of glue amount on delamination resistance for $Q$. rosea(a), $P$. venosa $(\mathbf{b})$ and $D$.

6 guianensis (c)

7 Fig. 3 Influence of Pressure (1) and CAT(2) on delamination resistance for Q. rosea(a), P. venosa

8 (b) and D. guianensis (c).

$9 \quad$ Fig.4 Block shear test results ( $2^{\text {nd }}$ set of tests) for individual values (a) and mean values (b) 10 current minimum requirements for production control (black lines) and Aicher and Ohnesorge 11 proposals (dotted lines).

12 Fig.5 Influence of D. guianensis lamellae thickness on delamination

13

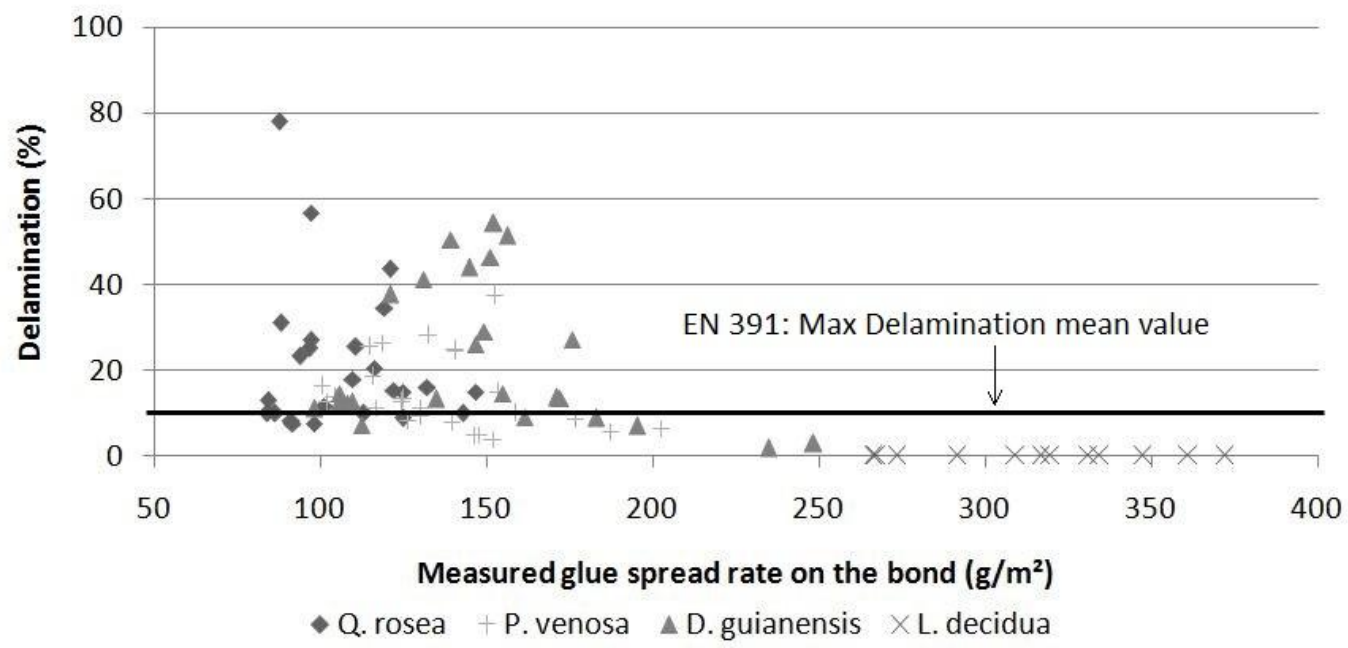

14

15 Fig.1 Influence of measured glue spread rate on delamination results

16

(a)

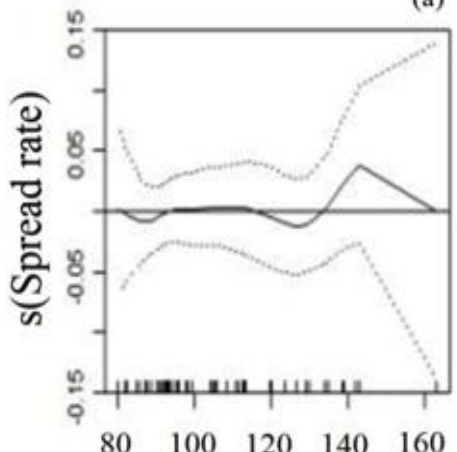

$\begin{array}{lllll}80 & 100 & 120 & 140 & 160\end{array}$

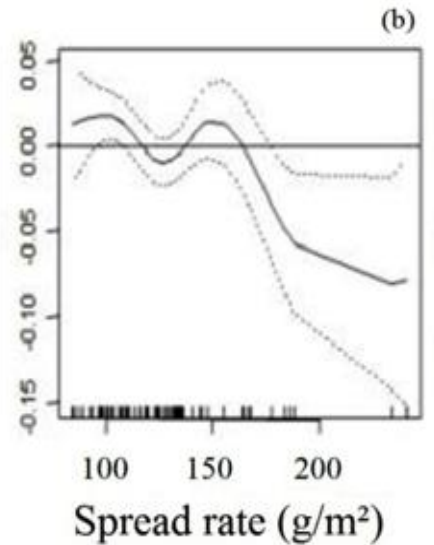

(b)

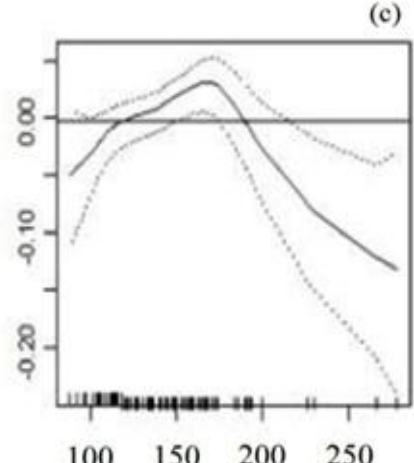

$\begin{array}{llll}100 & 150 & 200 & 250\end{array}$

(c) 
$1 \quad$ Fig.2 Influence of glue amount on delamination resistance for $Q$. rosea(a), P. venosa (b) and $D$. 2 guianensis $(\mathbf{c})$

3

(a1)

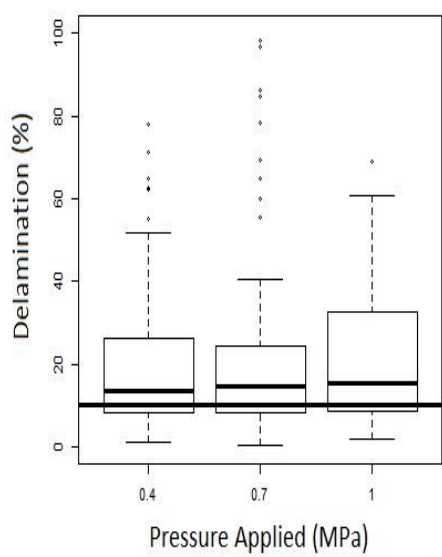

(a2)

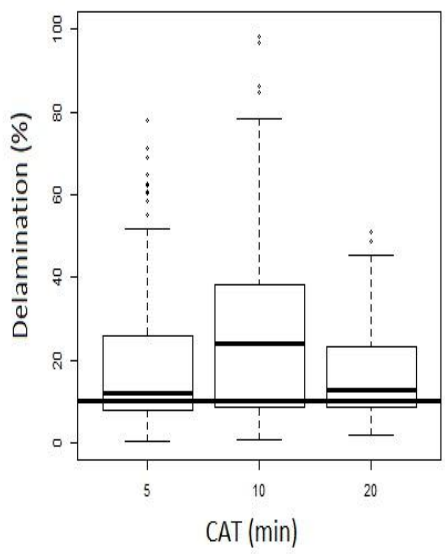

(b1)

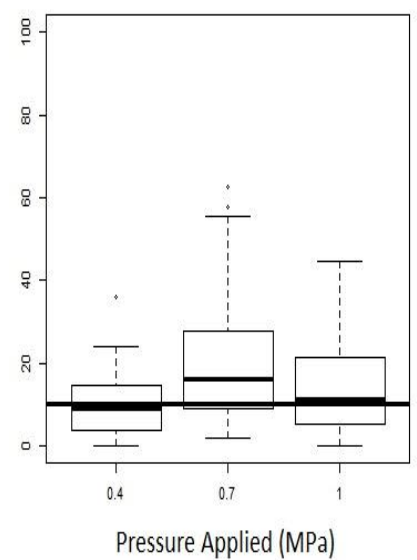

(b2)

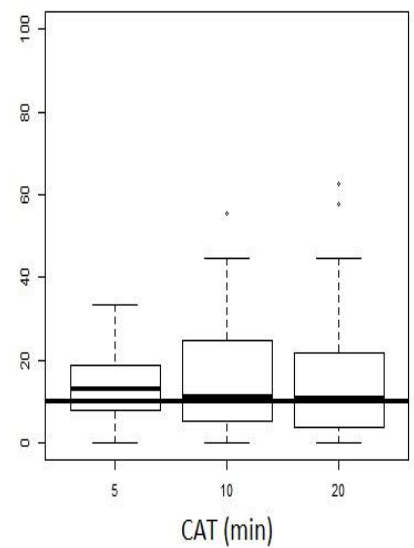

(c1)

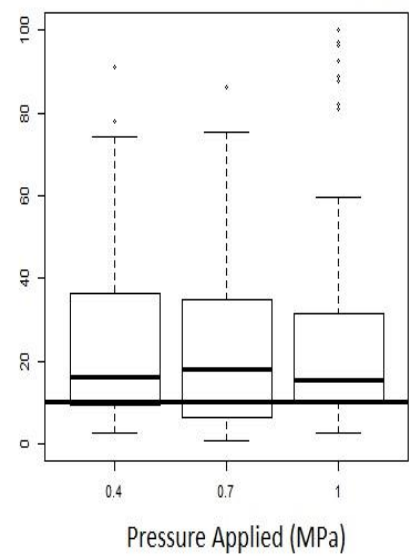

(c2)

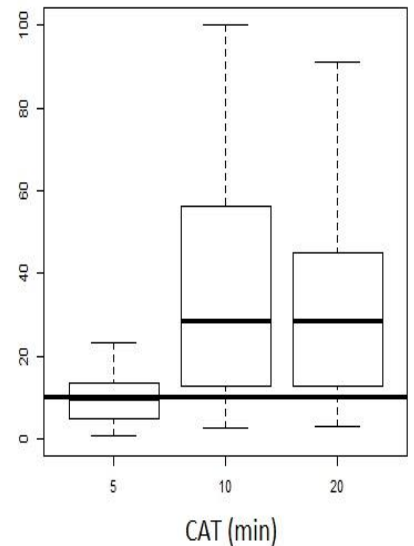

$5 \quad$ Fig.3 Influence of Pressure (1) and CAT (2) on delamination resistance for $Q$. rosea(a), $P$. 6 venosa (b) and D. guianensis (c) 


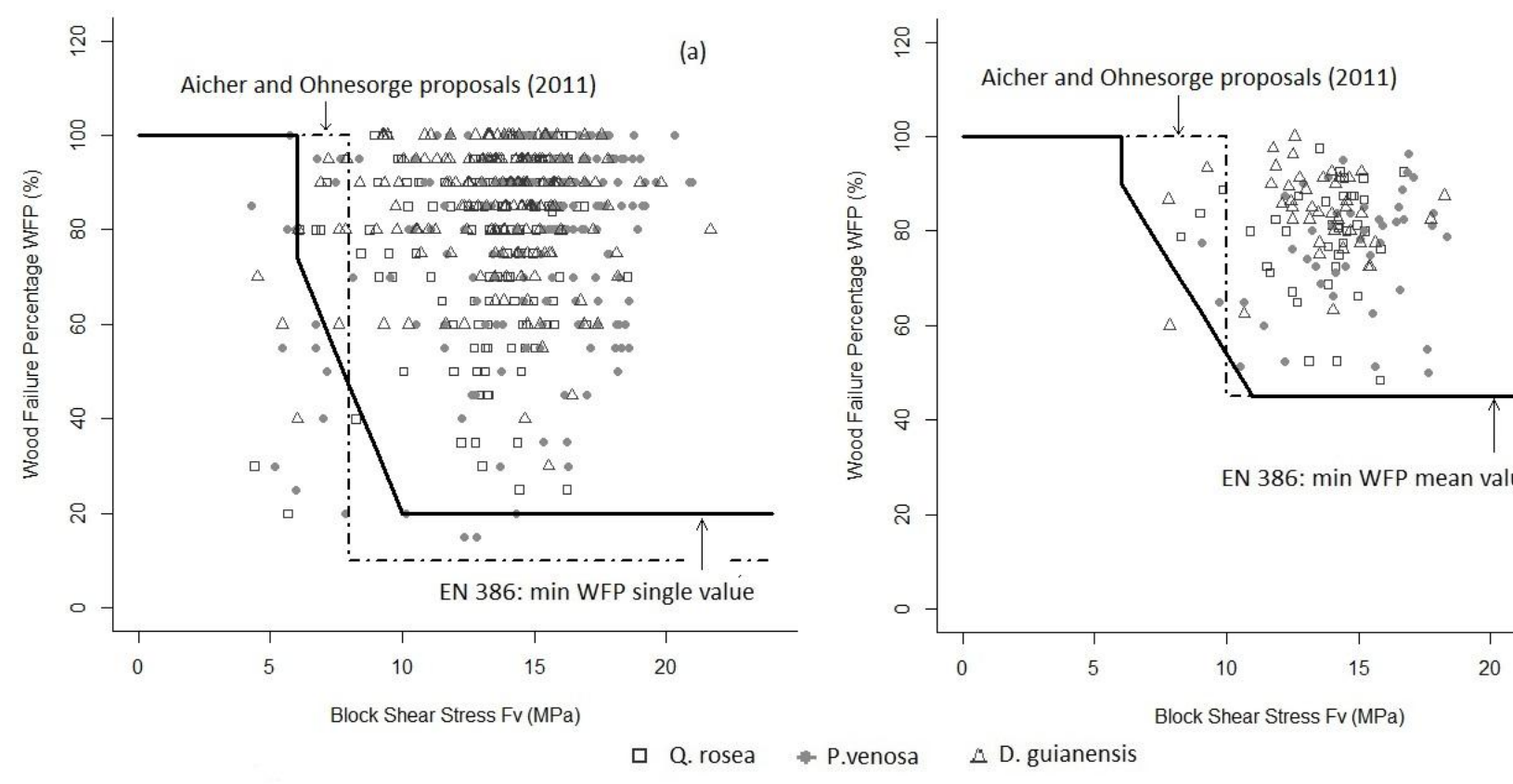

1

Fig.4 Block shear test results ( $2^{\text {nd }}$ set of tests) for individual values (a) and mean values (b) -

3 current minimum requirements for production control (black lines) and Aicher and Ohnesorge

4 proposals (dotted lines).

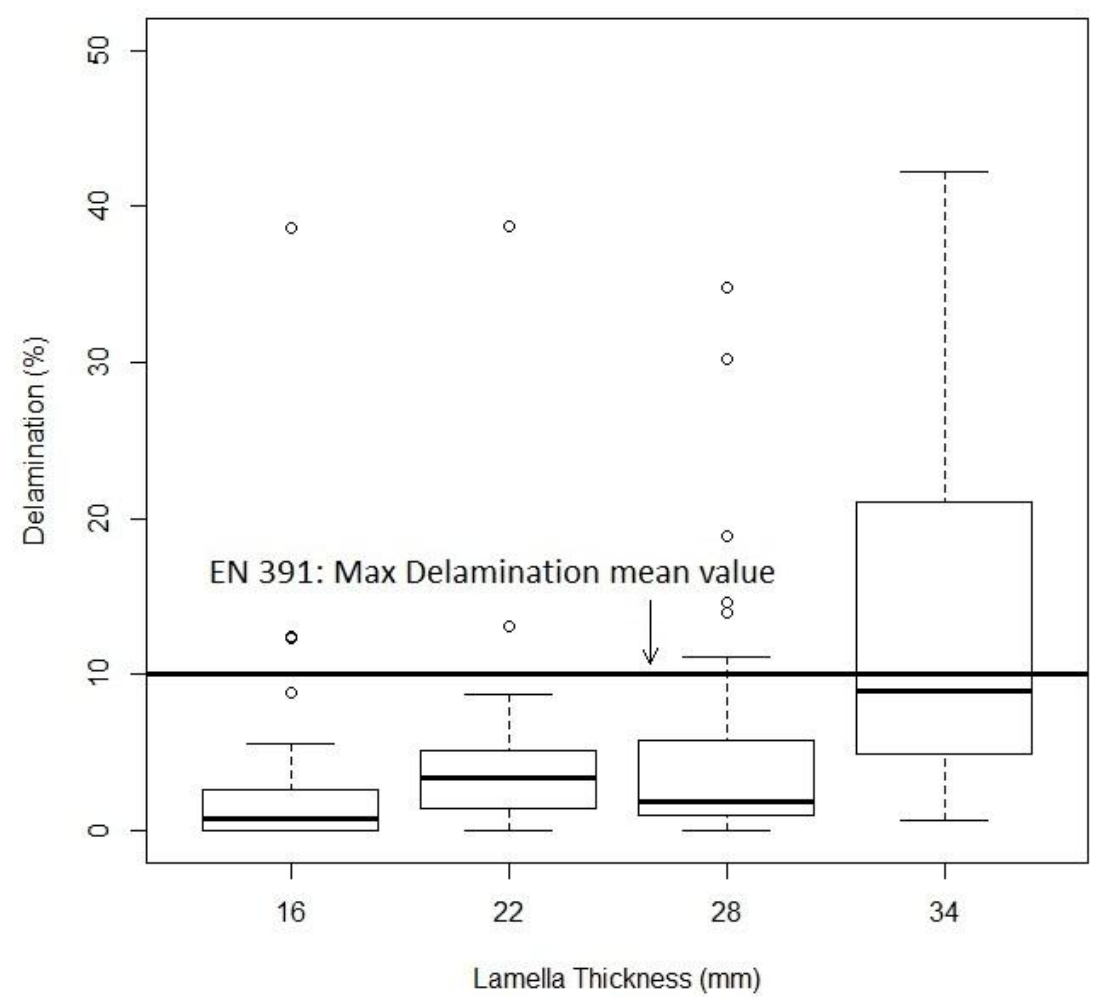

$7 \quad$ Fig.5 Influence of D. guianensis lamellae thickness on delamination 